\title{
Optimized PFoPID Control Design of Grid Connected PV Inverter for MPPT
}

\author{
Meble Varghese \\ $A B Q$ Seeb, Muscat \\ Al Khoudh St, Seeb, Muscat, Oman \\ meblevarghese12@gmail.com
}

\begin{abstract}
Maximum Power Point Tracking (MPPT) is a widely used controlling technique for extracting more power from solar cells of PV modules. This work intends to model a new "passive fractional-order proportional-integral-derivative (PFoPID) controller" for PV inverter by reshaping energy, such that the MPPT is achieved via P\&O system under varied atmospheres. As per the passivity concept, storage associated with the DC-link current, voltage, and q-axis current is modeled for a PV system and they are examined systematically. In this work, the residual energy is reshaped by the PFoPID controller, where the controlling parameters are tuned optimally by Grey Wolf Optimization with Self-adaptiveness (GWO-SA) approach. Finally, evaluation is performed for substantiating the efficiency of the GWO-SA based PFoPID controller over other controllers.
\end{abstract}

Keywords: MPPT; Pfopid Controller; P\&O System; Photo Voltaic; GWO-SA Model.

\begin{tabular}{ll} 
Nomenclature & \\
\hline Abbreviations & Descriptions \\
\hline FOINC & Fractional Order control based INC \\
FLC & Fuzzy Logic Controller \\
IAE & Integral of Absolute Error \\
INC & Incremental Conductance \\
MFO & Moth Flame Optimization \\
MPPT & Maximum Power Point Tracking \\
ORB & Optimum-Relation-Based \\
PFoPID & Passive Fractional-order Proportional-Integral-Derivative \\
PBC & Passivity-Based Control \\
PCU & Power Conditioning Unit \\
PV & Photo Voltaic \\
POFO & Perturbation Observer based Fractional-Order \\
P\&O & Perturb \& Observe \\
PSO & Particle Swarm Optimization \\
RESs & Renewable Energy Sources \\
SECS & Solar Energy Conversion System \\
SMC & Sliding-Mode Controller \\
SMSPO & Sliding-Mode State and P\&O \\
TSR & Tip Speed Ratio \\
WECS & Wind Energy Conversion Systems \\
\hline
\end{tabular}

\section{Introduction}

Because of the rising necessity for energy, researchers are focusing more on RES like wind energy, fuel cell, and PV [6] [7]. Amongst the different RES, PV is commonly deployed owing to its relatively reasonable cost and ease of access for solar power [8] [9]. The PV generation was deployed either in standalone mode or in grid connection mode. Consequently, the output voltage of PV varies with changes in temperature and solar irradiation. The MPPT technique presents the highest power at all 
environmental states and it is united with an electronic converter, which finally offers a controlled power to load [10] [11] [12].

The primary elements of a PV oriented system include a PV panel, PCU, and MPPT controller [13]. The efficacy of the trade connected PV panels is relatively minimal and as a result, a substantial power loss happens in the system. The most important issue is to cope with the nonlinear output features of the PV panel with unbalanced variations in solar irradiance and ambient temperature. In addition, to amplify the power output of PV, MPP has to be tracked effectually.

There were diverse MPPT techniques [14] deployed for solar and wind energy systems. On considering the MPPT models for WECS systems, three techniques such as P\&O; TSR, and ORB methods are usually deployed. The MPPT model for SECS systems includes techniques such as voltage tracing; P\&O and INC. All these approaches own certain disadvantages and advantages [17] [18] [19]. Thus, the researchers must choose the most suitable controlling approach for MPPT based PV systems [15].

The main contribution of this work is to propose the hybrid algorithm for the residual energy, which is reshaped by the PFoPID controller. In addition, the controlling parameters are tuned optimally by proposed Grey Wolf Optimization with Self-adaptiveness (GWO-SA) approach.

The paper is arranged as follows: The reviews are demonstrated in Section 2. Section 3 portrays the microgrid linked PV inverter system. Section 4 explains the modelling of the PFoPID controller for MPPT. Section 5 depicts the GWO-SA algorithm for optimal tuning of parameters. Section 6 portrays the results and the work is concluded by section 7 .

\section{Literature Review}

\subsection{Related Works}

In 2020, Salah et al. [1] have presented an adapted controlling scheme for developing the dynamics of PV using FoPID controller. In this work, optimal tuning of FoPID controller was carried out by exploiting the PSO approach. In addition, MFO oriented optimization was employed in the adopted work for improving the PV performance at diverse operating backgrounds. In the end, the adopted model has exposed excellent transient responses at diverse operational scenarios.

In 2018, Yang et al. [2] have presented a new Passive "PFoPID controller" that adopted the energy reshaping model. Accordingly, the MPPT was accomplished using the P\&O technique. Moreover, a storage function was modelled primarily for a PV system as per the "passivity concept". In this concept, the significant features of all terms were systematically investigated. Furthermore, the important parameters were preserved for facilitating the necessary features of the PV system.

In 2018, Mujahed et al. [3] have introduced a novel scheme for optimal modeling of FOINC-MPPT. The most important objective of this scheme was to build up a more proficient and robust MPPT model, by which the tracking performance was improved over the existing tracking models. This approach has guaranteed fast dynamics and superior tracking precision under miscellaneous atmospheric states. In the end, execution outcomes portrayed the superiority of the presented scheme over other schemes.

In 2018, Hong et al. [4] have made an analysis of the Taguchi-oriented MPPT approach, in which the "insolation and temperature" were regarded as "input and noise" for the PV system. In addition during the MPPT process, FLC was tuned optimally using the PSO approach. Accordingly, a PV system was deployed for illustrating the outcomes attained by the robust MPPT design of the adopted method.

In 2018, Yang et al. [5] have analyzed an adaptive and robust POFO-SMC PV inverter, which was linked with the power grid. Accordingly, an MPPT scheme on the INC method with diverse step sizes was introduced for producing the maximal solar energy at diverse climatic situations. In addition, the SMSPO model was deployed for estimating the mutual effects of PV inverters proficiently.

\section{Microgrid linked PV Inverter System}

The single-phase PV inverter is modelled as revealed in Fig.1 [12]. Assume $\mathrm{B}_{\mathrm{q}}$ and $\mathrm{B}_{\mathrm{s}}$ as the counts of PV cells arranged in parallel and series in that order. Here, the relationship amongst the output current and voltage is specified by Eq. (1), in which output current of PV is denoted by $\mathrm{I}_{\mathrm{qu}}$, B refers to ideality factor of $\mathrm{p}$-n junction, $\mathrm{I}_{\mathrm{qh}}$ signifies cell's photocurrent, $\mathrm{C}_{\mathrm{c}}$ indicates the temperature of the cell, $\mathrm{K}$ points out Boltzman's constant, $R_{s}$ refers to the resistance of cell series, $p$ refers to electron charge, $V_{\mathrm{dc}}$ and $I_{q u}$ 
denotes PV output voltage and current and $I_{s}$ refers to reverse saturation current of cell. $I_{q h}$ is determined as in Eq. (2) and the deviation of $I_{S}$ in terms of temperature is determined as per Eq. (3).

$$
\begin{aligned}
& \mathrm{I}_{\mathrm{qu}}=\mathrm{B}_{\mathrm{q}} \mathrm{I}_{\mathrm{qh}}-\mathrm{B}_{\mathrm{q}} \mathrm{I}_{\mathrm{s}}\left(\exp \left[\frac{\mathrm{p}}{\mathrm{MKC}_{\mathrm{c}}}\left(\frac{\mathrm{V}_{\mathrm{dc}}}{\mathrm{B}_{\mathrm{s}}}+\frac{\mathrm{I}_{\mathrm{qu}} \mathrm{R}_{\mathrm{s}}}{\mathrm{B}_{\mathrm{q}}}\right)\right]-1\right) \\
& \mathrm{I}_{\mathrm{qh}}=\left[\mathrm{I}_{\mathrm{sc}}+\mathrm{K}_{\mathrm{i}}\left(\mathrm{C}_{\mathrm{c}}-\mathrm{C}_{\mathrm{ref}}\right)\right] \frac{\mathrm{s}}{1000} \\
& \mathrm{I}_{\mathrm{s}}=\mathrm{I}_{\mathrm{RS}}\left[\frac{\mathrm{C}_{\mathrm{c}}}{\mathrm{C}_{\text {ref }}}\right]^{3} \exp \left[\frac{\mathrm{pF} \mathrm{F}_{\mathrm{g}}}{\mathrm{MK}}\left(\frac{1}{\mathrm{C}_{\text {ref }}}-\frac{1}{\mathrm{C}_{\mathrm{c}}}\right)\right]
\end{aligned}
$$

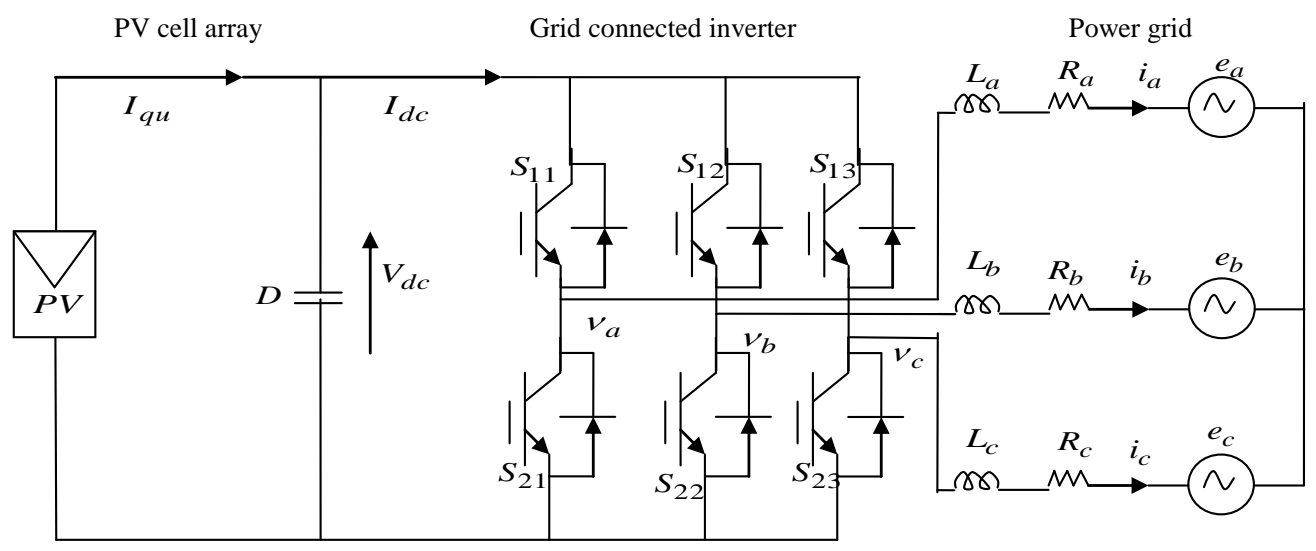

Fig. 1. Modelling of 3-phase 2-level PV inverter

The dynamics of 2-level 3-phase PV inverter in dq the frame are revealed by Eq. (4), in which $e_{d}, e_{p}, i_{d}, i_{p}, u_{d}, u_{p}$ signifies the dq -axis elements of PV inverter grid voltage, current, and voltage output, in that order. The inductance and resistance are pointed out by $L$ and $R$ and $\omega$ denotes the frequency of AC grid [13].

$$
\left\{\begin{array}{l}
u_{d}=e_{d}+R i_{d}+L \frac{d i_{d}}{d t}+\omega L i_{p} \\
u_{p}=e_{p}+R i_{p}+L \frac{d i_{d}}{d t}-\omega L i_{d}
\end{array}\right.
$$

The power balanced between the input of $\mathrm{AC}$ and output of DC is specified by Eq. (5). Here, $\mathrm{I}_{\mathrm{dc}}$ and $\mathrm{V}_{\mathrm{dc}}$ refers to the input current and voltage of $\mathrm{PV}$ inverter.

$$
e_{d} i_{d}+e_{p} i_{p}=V_{d c} I_{d c}
$$

The dynamics of DC is attained by using the "Kirchhoff's current law" as exposed in Eq. (6), where $A$ indicate the capacitance of the DC bus.

$$
\mathrm{D} \frac{\mathrm{dV} \mathrm{dc}}{\mathrm{dt}}=\mathrm{I}_{\mathrm{qu}}-\mathrm{I}_{\mathrm{dc}}=\mathrm{I}_{\mathrm{qu}}-\frac{\mathrm{e}_{\mathrm{d}} \mathrm{i}_{\mathrm{d}}+\mathrm{e}_{\mathrm{p}} \mathrm{i}_{\mathrm{p}}}{\mathrm{V}_{\mathrm{dc}}}
$$

This work makes use of the P\&O model [14] for tracking the MPP capably under diverse atmospheric conditions.

\section{Modelling of PFoPID Controller for MPPT}

\subsection{Fo-PID control}

"Fractional-order calculus is an overview of differentiation and integration". Eq. (7) point up the modelling of the fundamental operator ${ }_{\alpha} \mathrm{T}_{t}^{\alpha}$, here $t$ and a denotes upper and lower limits and $\alpha \in \mathfrak{R}$ specify the operating order [15]. 


$$
\alpha \mathrm{T}_{\mathrm{t}}^{\alpha}= \begin{cases}\frac{\mathrm{d}^{\alpha}}{\mathrm{dt}^{\alpha}}, & \alpha>0 \\ 1, & \alpha=0 \\ \int_{\mathrm{a}}^{\mathrm{t}}(\mathrm{d} \tau)^{-\alpha} & \alpha<0\end{cases}
$$

Consequently, RL is exploited with Gamma function $\Gamma($.$) as exposed in Eq. (8), in which n point out$ the 1st integer that is higher than $\alpha$. Eq. (8) shows the formulation for RL description in the FoPID model.

$$
\begin{aligned}
& { }_{\alpha} T_{t}^{\alpha} f(t)=\frac{1}{\Gamma(n-\alpha)} \frac{d^{n}}{d t^{n}} \int_{a}^{t} \frac{f(\tau)}{(t-\tau)^{\alpha-n+1}} d \tau \\
& { }_{\alpha} T_{t}^{\alpha} f(t)=\frac{1}{\Gamma(\alpha)} \int_{a}^{t}(t-\tau)^{\alpha-1} f(\tau) d \tau
\end{aligned}
$$

The Laplace transformation of Eq. (8) is shown in Eq. (10), in which the Laplace operator is indicated by $\ell\{$.$\} .$

$$
\int_{0}^{\alpha}{ }_{0} \mathrm{~T}_{\mathrm{t}}^{\alpha} \mathrm{f}(\mathrm{t}) \mathrm{e}^{-\mathrm{st}} \mathrm{dt}=\mathrm{s}^{\alpha} \ell\{\mathrm{f}(\mathrm{t})\}-\left.\sum_{\mathrm{K}=0}^{\mathrm{n}-1} \mathrm{e}^{\mathrm{K}}{ }_{0} \mathrm{~T}_{\mathrm{t}}^{\alpha-\mathrm{K}-1} \mathrm{f}(\mathrm{t})\right|_{\mathrm{t}=0}
$$

The transfer operation of FoPID control G(s) is exposed in Eq.(11) and here $\mathrm{k}_{\mathrm{T}} \mathrm{k}_{\mathrm{I}}$ and $\mathrm{k}_{\mathrm{q}}$ symbolize the derivative, integral, and proportional gain in that order.

$$
\mathrm{G}(\mathrm{s})=\mathrm{k}_{\mathrm{q}}+\frac{\mathrm{k}_{\mathrm{I}}}{\mathrm{s}^{\lambda}}+\mathrm{k}_{\mathrm{T}} \mathrm{s}^{\mu}
$$

In addition, $\mu$ and $\lambda$ point at the fractional differentiator and integrator order respectively.

\subsection{Passivity-oriented Controlling}

The PBC reshapes the energy of the system and it assists in allocating the energy function, which is equal to the variation among system energy and energy distributed by the controller. Eq. (12) demonstrates the model for energy balancing, where $A(t)$ denotes the storage function and $d(t)$ specifies a non-negative function.

$$
\begin{array}{lll}
\mathrm{A}[\mathrm{y}(\mathrm{t})]-\mathrm{A}[\mathrm{y}(0)]= & \int_{0}^{\mathrm{t}} \mathrm{v}(\mathrm{s}) \mathrm{x}(\mathrm{s})- & \mathrm{d}(\mathrm{t}) \\
\text { Stored } & \text { Supplied } & \text { Dis sipated }
\end{array}
$$

\subsection{PFoPID Controller}

Controller model: The state vector is represented as $y=\left(y_{1}, y_{2}, y_{3}\right)^{C}=\left(i_{d}, i_{p}, V_{d c}\right)^{c}$, the input is represented as $\mathrm{v}=\left(\mathrm{v}_{1}, \mathrm{v}_{2}\right)^{\mathrm{C}}=\left(\mathrm{u}_{\mathrm{d}}, \mathrm{u}_{\mathrm{p}}\right)^{\mathrm{C}}$ and output is represented as $\mathrm{x}=\left(\mathrm{x}_{1}, \mathrm{x}_{2}\right)^{\mathrm{C}}=\left(\mathrm{i}_{\mathrm{p}}, \mathrm{v}_{\mathrm{dc}}\right)^{\mathrm{C}}$. Consequently Eq. (4) and Eq. (6) is remodeled as shown in Eq. (13).

$$
\dot{\mathrm{y}}=\left(\begin{array}{c}
-\frac{\mathrm{R}}{\mathrm{L}} \mathrm{y}_{1}-\omega \mathrm{y}_{2}-\frac{\mathrm{e}_{\mathrm{d}}}{\mathrm{L}} \\
-\frac{\mathrm{R}}{\mathrm{L}} \mathrm{y}_{2}+\omega \mathrm{y}_{1}-\frac{\mathrm{e}_{\mathrm{p}}}{\mathrm{L}} \\
\frac{\mathrm{I}_{\mathrm{qu}}}{\mathrm{D}}-\frac{\mathrm{e}_{\mathrm{d}} \mathrm{y}_{1}+\mathrm{e}_{\mathrm{p}} \mathrm{y}_{2}}{\mathrm{Dy} \mathrm{y}_{3}}
\end{array}\right)+\left(\begin{array}{cc}
\frac{1}{\mathrm{~L}} & 0 \\
0 & \frac{1}{\mathrm{~L}} \\
0 & 0
\end{array}\right) \mathrm{V}
$$

The tracking error is described as $\mathrm{e}=\left(\mathrm{e}_{1}, \mathrm{e}_{2}\right)^{\mathrm{C}}=\left[\mathrm{i}_{\mathrm{p}}, \mathrm{i}_{\mathrm{p}}^{*}, \mathrm{~V}_{\mathrm{dc}}-\mathrm{V}_{\mathrm{dc}}^{*}\right]^{\mathrm{C}}$ that has to be differentiated until the control input $v$ turns out to be accurate. Thus Eq. (14) is formulated and $\mathrm{f}_{1}(\mathrm{y})$ and $\mathrm{f}_{2}(\mathrm{y})$ are evaluated as per Eq. (15) and Eq. (16).

$$
\begin{aligned}
& {\left[\begin{array}{c}
\bullet \\
e_{1} \\
\ddot{e_{2}}
\end{array}\right]=\left[\begin{array}{l}
\mathrm{f}_{1}(\mathrm{y}) \\
\mathrm{f}_{2}(\mathrm{y})
\end{array}\right]+D(\mathrm{y})\left[\begin{array}{c}
\mathrm{v}_{1} \\
\mathrm{v}_{2}
\end{array}\right]-\left[\begin{array}{c}
\mathrm{i}_{\mathrm{p}}^{*} \\
\ddot{\bullet}^{*} \\
\mathrm{~V}_{\mathrm{dc}}
\end{array}\right]} \\
& \mathrm{f}_{1}(\mathrm{y})=-\frac{\mathrm{R}}{\mathrm{L}} \mathrm{i}_{\mathrm{p}}+\omega \mathrm{i}_{\mathrm{d}}-\frac{\mathrm{e}_{\mathrm{p}}}{\mathrm{L}}
\end{aligned}
$$




$$
\begin{aligned}
& f_{2}(y)=\frac{i_{q u}}{D}-\frac{e_{d}\left(-\frac{R}{L} i_{p}-\omega i_{p}-\frac{e_{p}}{L}\right)+e_{p}\left(-\frac{R}{L} i_{p}+\omega i_{d}-\frac{e_{p}}{L}\right)}{D V_{d c}} \\
& -\frac{\left(e_{d} i_{d}+e_{p} i_{p}\right)}{D^{2} V_{d c}^{2}} I_{q u}+\frac{\left(e_{d} i_{d}+e_{p} i_{p}\right)^{2}}{D^{2} V_{d c}^{3}}
\end{aligned}
$$

with the control gain matrix $D(y)=\left[\begin{array}{cc}0 & \frac{1}{L} \\ -\frac{e_{d}}{L D V_{d c}} & -\frac{e_{p}}{L D_{d c}}\end{array}\right]$. For ensuring the I/O linearization, $D(y)$ must be nonsingular as revealed in Eq. (17).

$$
\operatorname{det}[\mathrm{D}(\mathrm{y})]=\frac{\mathrm{e}_{\mathrm{d}}}{\mathrm{L}^{2} \mathrm{DV} \mathrm{V}_{\mathrm{dc}}} \neq 0
$$

Eq. (17) is satisfied as the element $\mathrm{e}_{\mathrm{d}}$ has differed from zero. A "candidate storage function" for Eq. (14) is formulated as exposed in Eq. (18).

$$
\mathrm{A}\left(\mathrm{i}_{\mathrm{p}}, \mathrm{V}_{\mathrm{dc}}, \mathrm{I}_{\mathrm{dc}}\right)=\frac{1}{2}\left(\mathrm{i}_{\mathrm{p}}-\mathrm{i}_{\mathrm{p}}^{*}\right)^{2}+\frac{1}{2}\left(\mathrm{~V}_{\mathrm{dc}}-\mathrm{V}_{\mathrm{dc}}^{*}\right)^{2}+\frac{1}{2}\left(\frac{I_{\mathrm{dc}}}{\mathrm{D}}-\mathrm{V}_{\mathrm{dc}}^{*}\right)^{2}
$$

Eq. (19) can be accomplished by differentiating the storage function $A\left(\mathrm{i}_{\mathrm{p}}, \mathrm{V}_{\mathrm{dc}}, \mathrm{I}_{\mathrm{dc}}\right)$ with regard to time.

$$
\begin{aligned}
& \dot{A}\left(i_{p}, V_{d c}, I_{d c}\right)=\left(i_{p}-i_{p}^{*}\right)\left(-\frac{R}{L} i_{p}+\omega i_{d}-\frac{e_{p}}{L}+\frac{1}{L} v_{2}-i_{p}^{*}\right)+\left(\frac{I_{d c}}{D}-V_{d c}^{*}\right) \\
& {\left[\begin{array}{l}
V_{d c}-V_{d c}^{*}+\frac{I_{q u}}{D}-\frac{e_{d}\left(-\frac{R}{L} i_{d}+\omega i_{p}-\frac{e_{d}}{L}\right)+e_{p}\left(-\frac{R}{L} i_{p}+\omega i_{d}-\frac{e_{p}}{L}\right)}{D V_{d c}}- \\
\frac{\left(e_{d} i_{d}+e_{p} i_{p}\right)}{D^{2} V_{d c}^{2}} I_{q u}+\frac{\left(e_{d} i_{d}+e_{p} i_{p}\right)^{2}}{D^{2} V_{d c}^{3}}-\frac{e_{d}}{L D V_{d c}} v_{1}-\frac{e_{p}}{L D V_{d c}} v_{2}+V_{d c}^{*}
\end{array}\right]}
\end{aligned}
$$

The PFoPID control for system Eq. (14) is computed as per Eq. (20) with inputs $v_{1}$ and $v_{2}$ that are designed based on FoPID control as exposed in Eq. (21). In Eq. (21), PID control gains $\mathrm{k}_{\mathrm{Q} 1}, \mathrm{k}_{\mathrm{Q} 2}, \mathrm{k}_{\mathrm{I} 1}, \mathrm{k}_{\mathrm{I} 2}, \mathrm{k}_{\mathrm{D} 1}, \mathrm{k}_{\mathrm{D} 2}$, fractional differentiator order $\mu_{1}$ and $\mu_{2}$, fractional integrator order $\lambda_{1}$ and $\lambda_{2}$ are chosen for ensuring an improved convergence of tracking error as shown in Eq. (14).

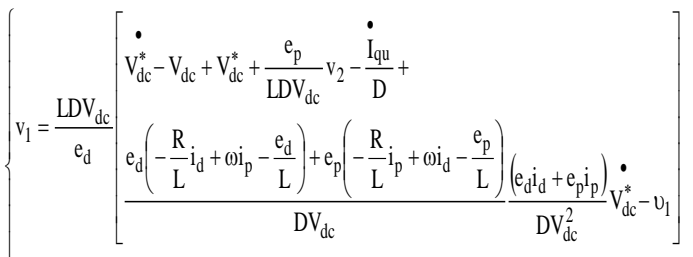

$$
\begin{aligned}
& v_{2}=L_{q}^{*}-\omega \omega L_{d}+R R_{p}^{*}+e_{p}-v_{2}
\end{aligned}
$$

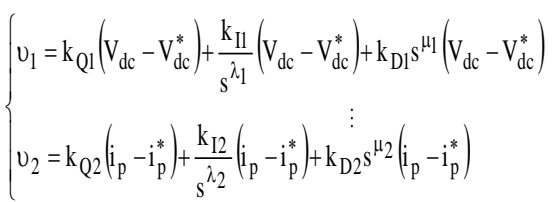

On replacing Eq. (20) and Eq. (21) into Eq. (19), along with Eq. (6) yields Eq. (22). In Eq. (22), $\mathrm{R}_{\mathrm{dc}}=\frac{\mathrm{V}_{\mathrm{dc}}^{2}}{\mathrm{e}_{\mathrm{d}} \mathrm{i}_{\mathrm{d}}+\mathrm{e}_{\mathrm{p}} \mathrm{i}_{\mathrm{p}}}$ refers to a virtual resistor.

$$
\begin{aligned}
& \dot{\mathrm{A}}\left(\mathrm{i}_{\mathrm{p}}, \mathrm{V}_{\mathrm{dc}}, \mathrm{I}_{\mathrm{dc}}\right)=-\frac{1}{\mathrm{DR}}\left(\dot{\mathrm{V}}_{\mathrm{dc}}-\dot{\mathrm{V}}_{\mathrm{dc}}^{*}\right)^{2}-\frac{\mathrm{R}}{\mathrm{L}}\left(\mathrm{i}_{\mathrm{p}}-\mathrm{i}_{\mathrm{p}}^{*}\right)^{2} \\
& -\left(\dot{\mathrm{V}}_{\mathrm{dc}}-\dot{\mathrm{V}}_{\mathrm{dc}}^{*}\right)^{2} \mathrm{v}_{1}-\frac{\mathrm{i}_{\mathrm{p}}-\mathrm{i}_{\mathrm{p}}^{*}}{\mathrm{~L}} \mathrm{v}_{2}
\end{aligned}
$$




\section{GWO-SA algorithm for Optimal Tuning of Parameters}

\subsection{Objective Function and Solution Encoding}

The parameters of PFoPID in Eq. (21) are optimally tuned via the GWO-SA scheme for obtaining optimal control. In this work, the objective is to lessen $\mathrm{F}(\mathrm{y})$ as stated in Eq. (23). Here, $\mathrm{k}_{\mathrm{Q}}, \mathrm{k}_{\mathrm{I}}, \mathrm{k}_{\mathrm{D}}, \lambda$, $\mu$ are provided as solutions that are diagrammatically shown in Fig. 2.

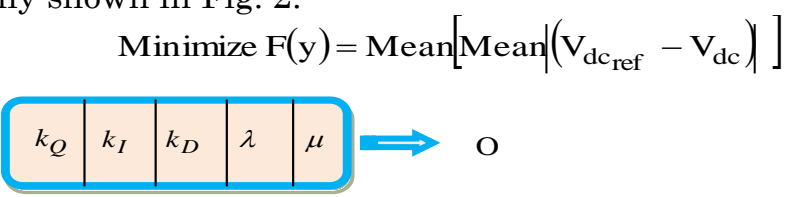

Fig. 2. Solution encoding

\subsection{GWO-SA Algorithm}

The GWO [16] algorithm portrays the hunting nature of grey wolves and its control hierarchy. There are 4 types of grey wolves, such as $\alpha, \eta, \zeta, \omega$ those that are used for carrying out the leadership hierarchy. The wolves namely, $\alpha, \eta$ and $\zeta$ are involved in the hunting process. Among them $\alpha$ are the leader that decides on hunting procedure and sleeping locations. Conversely, $\eta$ and $\zeta$ aids $\alpha$ in making choices. The encircling nature of wolves is revealed as in Eq. (24) and Eq. (25), here X and Y symbolizes the coefficient vectors, $\mathrm{O}_{\mathrm{p}}$ and $\mathrm{O}$ signifies the position vector of prey and grey wolves and signifies the present iteration. Accordingly, $\mathrm{X}$ and $\mathrm{Y}$ is evaluated as per Eq. (26) and Eq. (27), and $\mathrm{r}_{1}$ and $\mathrm{r}_{2}$ point out the arbitrary vectors that lie amongst $[0,1]$. As per the GWO-SA model, $a$ is computed as in Eq. (28), here ${ }^{\tau}$ points out the change of fitness as specified in Eq. (29), if $\mathrm{t} \neq 1$, otherwise, the value of $\tau$ is considered. In Eq. (29), $\mathrm{f}(\mathrm{t}-1)$ and $\mathrm{f}(\mathrm{t})$ indicates the previous and present iterations respectively.

$$
\begin{aligned}
& Z=\left|Y \cdot O_{p}(t)-O(t)\right| \\
& O_{p}(t+1)=O_{p}(t)-X . Z \\
& X=2 a \cdot r_{1}-a \\
& Y=2 r_{2} \\
& a=\tau *\left(2-1 *\left(\frac{2}{t_{\text {max }}}\right)\right) \\
& \tau=\frac{(f(t-1)-f(t))}{f(t-1)}
\end{aligned}
$$

The mathematical formulation for describing the hunting nature of wolf is shown by Eq. (30) to Eq. (35) and the final position of wolves is shown in Eq. (36).

$$
\begin{aligned}
& \mathrm{Z}_{\alpha}=\left|\mathrm{Y}_{1}-\mathrm{O}_{\alpha}-\mathrm{O}\right| \\
& \mathrm{Z}_{\eta}=\left|\mathrm{Y}_{2}-\mathrm{O}_{\eta}-\mathrm{O}\right| \\
& \mathrm{Z}_{\zeta}=\left|\mathrm{Y}_{3}-\mathrm{O}_{\zeta}-\mathrm{O}\right| \\
& \mathrm{O}_{1}=\mathrm{O}_{\alpha}-\mathrm{X}_{1} \cdot\left(\mathrm{Z}_{\alpha}\right) \\
& \mathrm{O}_{2}=\mathrm{O}_{\eta}-\mathrm{X}_{2} \cdot\left(\mathrm{Z}_{\eta}\right) \\
& \mathrm{O}_{3}=\mathrm{O}_{\zeta}-\mathrm{X}_{3} \cdot\left(\mathrm{Z}_{\zeta}\right) \\
& \mathrm{O}(\mathrm{t}+1)=\frac{\mathrm{O}_{1}+\mathrm{O}_{2}+\mathrm{O}_{3}}{3}
\end{aligned}
$$

\section{Results and Discussion}

\subsection{Simulation Procedure}

The presented work on PFoPID controller using the GWO-SA model was implemented in MATLAB and the results were accomplished. In this work, temperature and solar radiation were selected based on their rated values, e.g., $25^{\circ} \mathrm{C}$ and $1 \mathrm{~kW} / \mathrm{m} 2$. In addition, the current at $\mathrm{q}$ axis was maintained at zero. At such benchmark operating conditions, the output current of PV was maintained at 3.46 A, the voltage of DC link was maintained at $539.5 \mathrm{~V}$, and the output power of PV was maintained at $1867 \mathrm{~W}$. 


\subsection{IAE Index}

The IAE indices of GWO-SA based PFoPID controller over the compared existing controllers are shown in Table I. Here, the analysis was held concerning three cases namely, "Solar irradiation variation, Temperature variation, and Power grid voltage drop". As revealed in Table 1, the PFoPID controller has attained the smallest IAE indices and therefore it can perform better than the compared controllers owing to the energy reshaping and retainment of valuable terms. Particularly, the temperature variation of $\mathrm{IAE}_{\mathrm{I}_{\mathrm{q}}}$ using PFoPID is 82.31\%, 77.43\%, and 74.74\% better than PBC control, FoPID control, and PID correspondingly. Thus, the improvement of the optimized PFoPID controller is established from the simulated outcomes.

Table 1: IAE indices of four controllers attained by the Proposed controller over the existing controllers with respect to three scenarios

\begin{tabular}{llllll}
\hline Scenarios & IAE Indices & PBC & FoPID & PID & PFoPID \\
\hline Solar irradiation variation & $\mathrm{IAE}_{\mathrm{V}_{\mathrm{dc}}}$ & 0.4357 & 0.4412 & 0.4484 & 0.3901 \\
& $\mathrm{IAE}_{\mathrm{I}_{\mathrm{q}}}$ & 0.1611 & 0.1732 & 0.1837 & 0.1407 \\
\multirow{3}{*}{ Temperature variation } & $\mathrm{IAE}_{\mathrm{V}_{\mathrm{dc}}}$ & 0.5262 & 0.5431 & 0.5587 & 0.4778 \\
& $\mathrm{IAE}_{\mathrm{I}_{\mathrm{q}}}$ & 0.2013 & 0.2140 & 0.2217 & 0.1657 \\
& $\mathrm{IAE}_{\mathrm{V}_{\mathrm{dc}}}$ & 0.6863 & 0.7249 & 0.7529 & 0.6277 \\
& $\mathrm{IAE}_{\mathrm{I}_{\mathrm{q}}}$ & 0.2938 & 0.3207 & 0.3413 & 0.2476 \\
\hline
\end{tabular}

\subsection{Overall Cost Analysis}

Table 2 demonstrates the overall cost of the PFoPID controller over the compared existing controllers and the analysis was held concerning three cases namely, "Solar irradiation variation, temperature variation, and Power grid voltage drop". From the analysis, the PFoPID controller has accomplished minimal cost for all scenarios. Specifically, the overall cost of the PFoPID controller for temperature variation is $4.52 \%, 8.88 \%$, and $9.47 \%$ superior to PBC, FoPID, and PID controllers respectively.

Table 2: Overall Cost analysis attained by optimized PFoPID controller over the existing controllers with respect to three scenarios

\begin{tabular}{lllll}
\hline Scenarios & PBC & FoPID & PID & PFoPID \\
\hline Solar irradiation variation & 0.546 & 0.537 & 0.546 & 0.486 \\
Temperature variation & 0.752 & 0.788 & 0.793 & 0.718 \\
Power grid voltage drop & 0.895 & 0.919 & 0.925 & 0.851 \\
\hline
\end{tabular}

\subsection{Analysis on Overall Energy}

The overall energy attained by the PFoPID controller over the compared existing controllers is demonstrated by Fig. 3 and the analysis were held concerning three cases. On analyzing the energy, the PID control has attained the maximum value; therefore it offers a higher tracking error amongst 4 controllers. On the contrary, PFoPID control has the least tracking error and as a result, it can attain the most acceptable controlling performance.

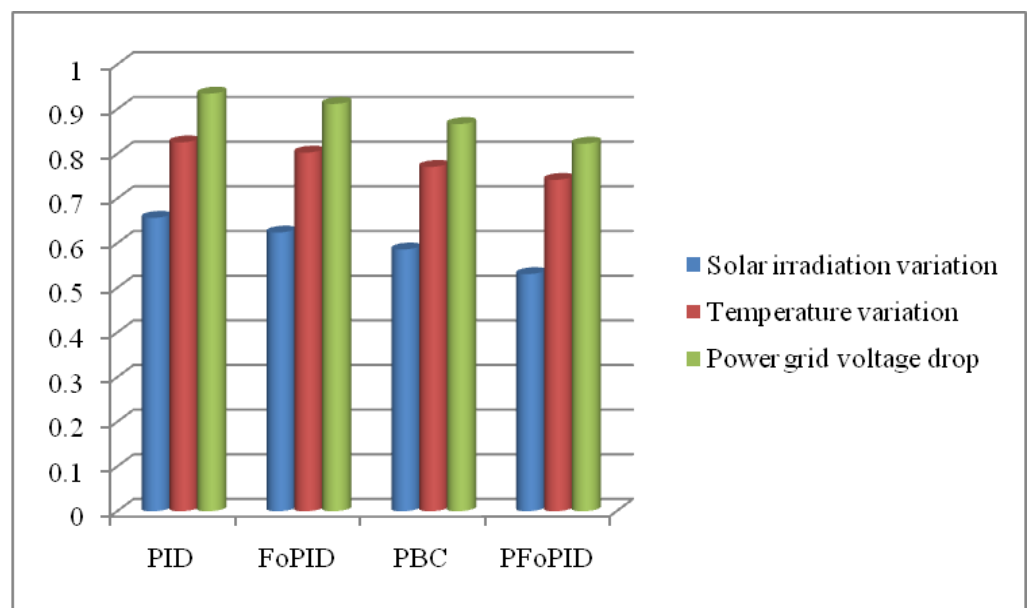

Fig. 3. Overall energy analysis of PFoPID controller over the existing controllers with respect to three scenarios 


\section{Conclusion}

This work has modeled the PFoPID controller for PV inverter by reshaping the energy. Accordingly, the MPPT was attained by deploying the $\mathrm{P} \& \mathrm{O}$ system under various conditions. Moreover, a storage function was built based on passivity theory and as a result, the physical features of entire variables were examined in a systematic order. Moreover, the controlling parameters of the PFoPID controller were tuned optimally using the GWO-SA model. In the end, the analysis was carried out to prove the enhancement of the suggested scheme. From the analysis, the PFoPID controller has accomplished minimal cost for all scenarios. Specifically, the overall cost of the PFoPID controller for temperature variation is $4.52 \%, 8.88 \%$, and $9.47 \%$ superior to PBC, FoPID, and PID controllers respectively. Thus, the superior performance of the GWO-SA model has been established effectively.

\section{References}

[1] Mohammed Salah Bouakkaz, Ahcene Boukadoum, Omar Boudebbouz, Nadir Fergani, Ammar Necaibia, "Dynamic performance evaluation and improvement of PV energy generation systems using Moth Flame Optimization with combined fractional order PID and sliding mode controller”, Solar Energy, vol. 199, pp. 411424, 15 March 2020.

[2] Bo Yang, Tao Yu, Hongchun Shu, Dena Zhu, Lin Jiang, "Energy reshaping based passive fractional-order PID control design and implementation of a grid-connected PV inverter for MPPT using grouped grey wolf optimizer”, Solar Energy, vol. 170, pp. 31-46, August 2018.

[3] Mujahed Al-Dhaifallah, Ahmed M. Nassef, Hegazy Rezk, Kottakkaran Sooppy Nisar, "Optimal parameter design of fractional order control based INC-MPPT for PV system”, Solar Energy, vol. 159, pp. 650-664, 1 January 2018.

[4] Ying-Yi Hong, Angelo A. Beltran, Arnold C. Paglinawan, "A robust design of maximum power point tracking using Taguchi method for stand-alone PV system, "Applied Energy, vol. 211, pp. 50-63, 1 February 2018.

[5] Bo Yang, Tao Yu, Hongchun Shu, Dena Zhu, Lin Jiang, "Perturbation observer based fractional-order sliding mode controller for MPPT of grid-connected PV inverters: Design and real-time implementation", Control Engineering Practice, vol. 79, pp. 105-125, October 2018.

[6] A. Elrayyah, Y. Sozer and M. Elbuluk, "Microgrid-Connected PV-Based Sources: A Novel Autonomous Control Method for Maintaining Maximum Power," IEEE Industry Applications Magazine, vol. 21, no. 2, pp. 19-29, March-April 2015.

[7] P. Kofinas, S. Doltsinis, A. I. Dounis, G. A. Vouros, "A reinforcement learning approach for MPPT control method of photovoltaic sources", Renewable Energy, vol. 108, pp. 461-473, August 2017.

[8] Hanane Yatimi, Elhassan Aroudam, "Assessment and control of a photovoltaic energy storage system based on the robust sliding mode MPPT controller", Solar Energy, vol. 139, pp. 557-568, 1 December 2016.

[9] Yie-Tone Chen, Yi-Cheng Jhang, Ruey-Hsun Liang, "A fuzzy-logic based auto-scaling variable step-size MPPT method for PV systems", Solar Energy, vol. 126, pp. 53-63, March 2016.

[10] C. Y. Yang, C. Y. Hsieh, F. K. Feng and K. H. Chen, "Highly Efficient Analog Maximum Power Point Tracking (AMPPT) in a Photovoltaic System," IEEE Transactions on Circuits and Systems I: Regular Papers, vol. 59, no. 7, pp. 1546-1556, July 2012.

[11] Md Fahim Ansari , S. Chatterji \& Atif Iqbal, "A fuzzy logic control scheme for a solar photovoltaic system for a maximum power point tracker", International Journal of Sustainable Energy, vol. 29, no.4, pp. 245-255, 2010.

[12] Kadri, R., Gaubert, J.P., Champenois, G, "An improved maximum power point tracking for photovoltaic gridconnected inverter based on voltage-oriented control", IEEE Trans. Ind. Electron, vol. 58, no. 1, pp. 66-75, 2011.

[13] Lalili, D., Mellit, A., Lourci, N., Medjahed, B., Berkouk, E.M., Input output feedback linearization control and variable step size MPPT algorithm of a grid-connected photovoltaic inverter. Renew. Energy 36, pp. 3282-3291, 2011.

[14] Alik, R., Awang, J., "Modified Perturb and Observe (P\&O) with checking algorithm under various solar irradiation", Sol. Energy, vol. 148, pp.128-139, 2017.

[15] Podlubny, I. Fractional Differential Equations. Academic Press, New York, 1999.

[16] S. Sharma, S. Bhattacharjee and A. Bhattacharya, "Grey wolf optimisation for optimal sizing of battery energy storage device to minimise operation cost of microgrid," in IET Generation, Transmission \& Distribution, vol. 10, no. 3, pp. 625-637, 2182016.

[17] Jan Bhasha Shaik,Ganesh V,"Deep Neural Network and Social Ski-Driver Optimization Algorithm for Power System Restoration with VSC - HVDC Technology",Journal of Computational Mechanics, Power System and Control (JCMPS),Volume 3, Issue 1, January 2020.

[18] Rupam Gupta Roy,Dibyendu Ghoshal,"Search and Rescue Optimization Algorithm - Second Order Sliding Mode Control: AUV Error Tracking", Journal of Computational Mechanics, Power System and Control (JCMPS),Volume 3, Issue 1, January 2020.

[19] Naresh Kumar Yadav,"Optimal ATC Enhancement Model: Analysis of the Effect of Thyristor-Controlled Series Compensation",Journal of Computational Mechanics, Power System and Control (JCMPS), Volume 2, Issue 1, January 2019. 